\title{
CARACTERIZAÇÃO ESTRUTURAL DA SÍLICA PROVENIENTE DA CINZA DO BAGAÇO DA CANA
}

\section{STRUCTURAL CHARACTERIZATION OF SILICA FROM SUGARCANE BAGASSE ASH}

\author{
Luma Freitas Corrêa ${ }^{1}$, Daniel Ângelo Macena ${ }^{1}$, Jaqueline Nascimento \\ da Silva ${ }^{1}$, Diego Ariça Cecatto ${ }^{1}$
}

${ }^{1}$ Universidade do Oeste Paulista - Unoeste, Faculdade de Ciências, Letras e Educação de Presidente Prudente - FACLEPP

e-mail: lumafreitas27@gmail.com¹ ${ }^{1}$ daniel@unoeste.br², jaqueline@unoeste.br ${ }^{3}$, diegoarica@unoeste.br ${ }^{4}$

RESUMO - A sílica ou dióxido de silício (SiO2) é um composto natural que atualmente é o oxido mais utilizado como precursor de novos materiais. Com alto grau de cristalinidade, pode ser empregada na produção de diversos produtos. Como se trata de um produto finito, surge então a necessidade de buscar alternativas para atender sua demanda. $O$ presente trabalho propõe a caracterização da cinza proveniente da cinza do bagaço da cana e a produção de um material que apresente maior grau de cristalinidade. A caracterização foi realizada através da difração de raio-x, após as amostras serem submetidas a diferentes tratamentos ácidos e calcinação. As análises dos difratogramas mostram que foi possível a obtenção do $\alpha$-quartzo que apresenta maior cristalinidade em relação a amostra sem nenhum tratamento, comprovando assim, que os tratamentos térmicos e ácidos foram satisfatórios. Além disso, o material obtido permite sua utilização na produção de diferentes tipos de seguimento.

Palavras-chave: cana de açúcar; sílica; caracterização; cristalinidade.

Recebido em: 03/06/2018

Revisado em: 03/09/2018

Aprovado em: 05/09/2018
ABSTRACT - The silicon or silicon dioxide $\left(\mathrm{SIO}_{2}\right)$ it's a natural compost that is the most used as the percursor of new materials. With a high level of crystallinity, it can be very usefull inside the elaboration of new products. As a finite product, there is a need to comply the demands in altenate ways. The current work comes up with an ash characterization that is provided from the sugar cane bagasse ash and the production of a material that presents an higher level of crystallinity. The characterization was maide thrugh the diffraction of an X-Ray after samples being submits inside different acid treatments and calcination. The diffractograms analyses demonstrate that it was possible to achieve the Alpha-Quatrz that presents an higher crystallinity with a comparison to the samples that were not receveing the treatment, proving this way, that thermal and acid treatments were effective. Beyond, the material obtains the utilization on different types of following up.

Keywords: sugarcane bagasse; silica; characterization; cristallinity. 


\section{INTRODUÇÃO}

A bioeletricidade, gerada através da combustão do bagaço da cana de açúcar, extremamente favorável ao meio ambiente, também possui malefícios, por assim dizer, uma vez que gera resíduos. Dentre os resíduos encontram-se as cinzas, resultantes do processo de limpeza das fornalhas da caldeira.

As cinzas têm sua composição variada, porém cerca de $85 \%$ em sua totalidade é composta por sílica. A sílica ou dióxido de silício $\left(\mathrm{SiO}_{2}\right)$ é um composto natural formado por dois elementos químicos abundantes na crosta terrestre, o oxigênio e o silício. É encontrada na natureza nas formas amorfa (sílica gel) e cristalina (quartzo) (TERRA FILHO; SANTOS, 2006).

A sílica em sua forma amorfa é um polímero inorgânico inerte, resistente, com alta porosidade, além disso ela permite sua modificação química que facilita a obtenção de compostos mais versáteis e com propriedades específicas (PRADO; FARIA; PADILHA, 2005). É encontrado na natureza abundantemente na forma de areia e quartzo. A forma mais comum é a $\alpha$-quartzo, em todas suas formas, o silício é rodeado tetraedricamente por quatro átomos de oxigênio. Cada vértice é compartilhado com outro tetraedro, formando assim um arranjo infinito. $\mathrm{O}$ que as diferencia são as maneiras com que as unidades de $\mathrm{SiO}_{2}$ estão ligadas umas nas outras (LEE, 1999). Além disso possuem em sua superfície os grupos silanóis ( $\mathrm{Si}-\mathrm{OH})$ que conferem polaridade e servem como sítios de ligações para as moléculas sililantes, permitindo a adsorção de moléculas de água (OLIVEIRA, 2014).

O $\alpha$-quartzo é um material importantíssimo para aplicações industriais. Ele pode ser utilizado em sua forma de areia para produção de agregados na construção civil. Além disso, em diferentes graus de pureza, suas propriedades físicas e a disponibilidade de cristais com alto grau de cristalinidade permitem que o $\alpha$-quartzo possa ser empregado na produção de tintas, esmaltes, porcelanas, louças sanitárias, vidros convencionais, produção de dispositivos piezelétricos para medidas de grandezas físicas, entre outros (GUZZO, 2008).

O quartzo natural encontrado na natureza não é o bastante para suprir sua demanda. Surge então, a necessidade de buscar alternativas para atender a demanda do material. Uma dessas alternativas é a utilização do subproduto cinza do bagaço da cana para a obtenção da sílica. A obtenção da sílica a partir da cinza do bagaço da cana é feita após uma simples calcinação onde toda a matéria orgânica será decomposta pela temperatura. Esse processo dará resultado a uma sílica com baixa pureza, devido à presença de óxidos metálicos e matéria orgânica residual. A pureza da sílica vai depender do destino de sua aplicação (OLIVEIRA, 2014).

O presente trabalho propõe a caracterização estrutural da sílica obtida através do subproduto cinza do bagaço da cana, e a produção de um material com maior cristalinidade em relação ao seu principal componente, o dióxido de silício $\left(\mathrm{SiO}_{2}\right)$.

\section{MATERIAL E MÉTODOS}

\subsection{Preparo da amostra}

Foi utilizada cinza proveniente da queima do bagaço da cana para a geração de energia. $O$ material foi submetido a dois tratamentos hidrotérmicos em diferentes meios ácidos como descrito no Quadro 1. Esses tratamentos foram realizados em Bloco Microdigestor de Kjeldahl da marca Quimis, modelo $Q-327 B 28 M 8$ tubos. 
Quadro 1. Condições dos tratamentos ácidos empregados na cinza do bagaço da cana.

\begin{tabular}{|c|c|c|c|}
\hline AMOSTRA & MEIO & $\begin{array}{l}\text { TEMPERATURA } \\
\left({ }^{\circ} \mathrm{C}\right)\end{array}$ & $\begin{array}{c}\text { TEMPO DE } \\
\text { TRATAMENTO } \\
\text { (h) }\end{array}$ \\
\hline 1 & Sem tratamento & - & - \\
\hline 2 & $\begin{array}{l}\mathrm{HNO}_{3} \text { concentrado } \\
\mathrm{H}_{2} \mathrm{O}_{2} \text { concentrado }\end{array}$ & 120 & 2 \\
\hline 3 & $\begin{array}{l}\mathrm{H}: \mathrm{PO} 42,0 \mathrm{~mol} . \mathrm{L}^{-1} \\
\mathrm{H}_{2} \mathrm{SO} 42,0 \mathrm{~mol} . \mathrm{L}^{-1}\end{array}$ & 120 & 2 \\
\hline
\end{tabular}

Fonte: Próprio autor.

Após tratamento ácido o material foi calcinado em forno tipo mufla EDG - 3000, com taxa de aquecimento de $20^{\circ} \mathrm{C} /$ min com tempo de permanência de 1 hora nos patamares de $500^{\circ} \mathrm{C}, 600^{\circ} \mathrm{C}$ e $700^{\circ} \mathrm{C}$.

\subsection{Caracterização por meio de difração de} raio $\times(D R X)$

Para a realização da caracterização estrutural usou-se o difratômetro da Shimadzu modelo XRD 600 , utilizando uma radiação de $\mathrm{Cu}(\mathrm{K} \alpha$ $\lambda \sim 1,54 \AA$ A), radiação característica em uma varredura angular de $10^{\circ}$ até $90^{\circ}(2 \theta)$. Para identificação dos materiais utilizou-se 0 programa Search Match e o banco de dados PDF (Power Diffraction Files), disponível no próprio programa. Foram analisadas amostras apenas com o tratamento ácido sem calcinação e também amostras dos tratamentos ácidos com emprego da calcinação.

\section{RESULTADOS}

\subsection{Amostras com tratamento ácido}

A Figura 1 representa 0 difratograma de raios $X$ das amostras de cinza do bagaço da cana. A linha preta é referente a cinza sem nenhum tipo de tratamento (Amostra 1), a linha vermelha representa a cinza com tratamento de ácido nítrico mais peróxido de hidrogênio (Amostra 2), já a linha azul representa a cinza com tratamento de ácido sulfúrico e ácido fosfórico (Amostra 3).
Figura 1 - Difratograma de raio $x$ das amostras de cinza do bagaço da cana.

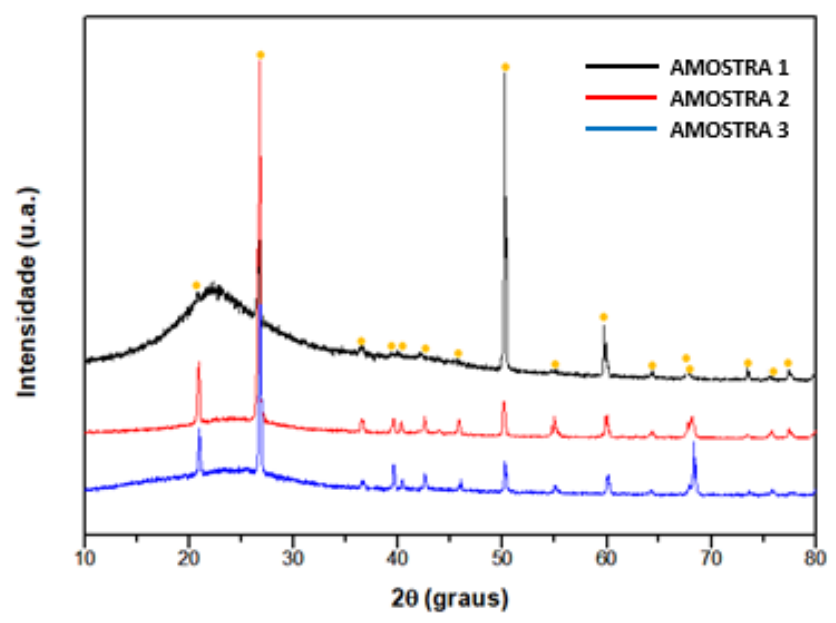

Fonte: Próprio autor

\subsection{Amostras com tratamento térmico após tratamento ácido}

A Figura 2 apresenta 0 difratograma de raio $x$ das amostras de cinza do bagaço da cana. A linha vermelha representa a cinza com tratamento de ácido nítrico mais peróxido de hidrogênio (Amostra 2) e a linha azul representa a cinza com tratamento de ácido sulfúrico e ácido fosfórico (Amostra 3), após serem submetidas a calcinação em forno tipo mufla com taxa de aquecimento de $20^{\circ} \mathrm{C} / \mathrm{min}$ com tempo de permanência de 1 hora nos patamares de $500^{\circ} \mathrm{C}, 600^{\circ} \mathrm{C}$ e $700^{\circ} \mathrm{C}$.

Figura 2. Difratograma de raio $x$ das amostras de cinza do bagaço da cana com tratamento térmico e ácido.

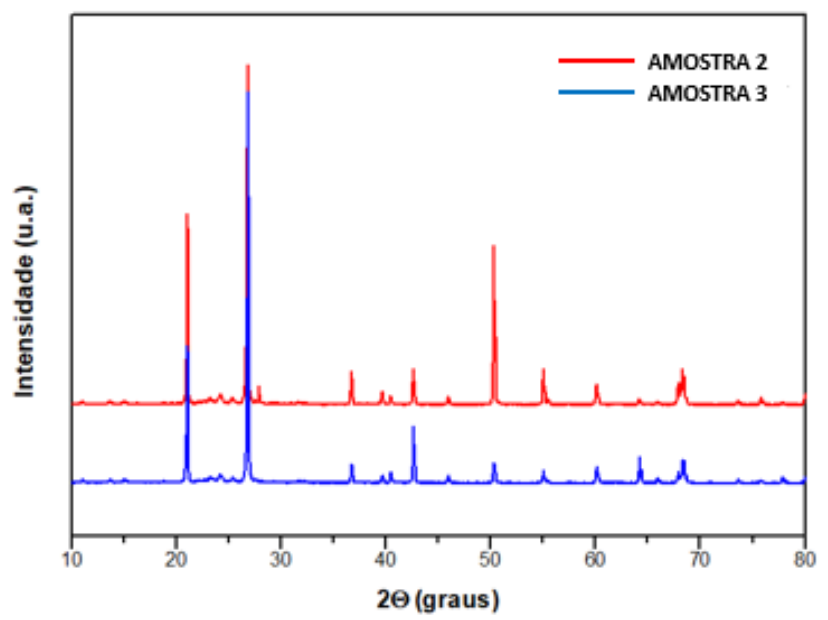

Fonte: Próprio autor. 


\section{DISCUSSÃO}

\subsection{Amostras com tratamento ácido}

No difratograma representado

pela Figura 1, foi identificado os picos característicos do dióxido de silício (SiO2) em sua forma de quartzo, presentes na amostra 1, que representa o elemento em maior quantidade na cinza em si. Nota-se que os picos encontrados são compatíveis com dados de quartzo presentes no banco de dados Power Diffraction Files, porém nem todos os picos são coincidentes, existem pequenos deslocamentos entre eles. Observa-se um halo em torno de 15 a 300 , que está associado à estrutura amorfa da cinza (PAIVA, 2016).

Ao analisar a amostra 2 no difratograma da Figura 1, nota-se que temos a mesma fase identificada (quartzo) em relação a amostra 1 , os resultados foram comparados com o banco de dados Power Diffraction Files. $\mathrm{E}$ visível como os picos ficaram mais correspondentes com a ficha cristalográfica comparada após esse tratamento ácido, mostrando também uma maior intensidade dos mesmos. Com relação à estrutura amorfa nota-se uma significativa diminuição da banda, que é um indicativo de que o tratamento ácido conseguiu quebrar a estrutura da amostra, porém sem alteração na fase identificada.

Ao analisar a amostra 3 no difratograma da Figura 1 nota-se que a mesma fase é identificada, compatível com a ficha cristalográfica de quartzo presente no banco de dados Power Diffraction Files. Os picos se mostram mais alinhados em relação à amostra 1 mostrando que o tratamento ácido modificou a estrutura do material além de aumentar sua cristalinidade. Com relação ao indicativo de estrutura amorfa esse tratamento ácido se mostrou menos eficiente que o tratamento empregado na amostra 2, porém houve significativa diminuição desse tipo de estrutura (PAIVA, 2016).

Observou-se que os

tratamentos ácidos foram positivos em diminuir a quantidade de material amorfo presente na amostra além de aumentar a correspondência entre o difratograma e as fichas cristalográficas, ou seja, sua cristalinidade (OLIVEIRA, 2014).

\subsection{Amostras com tratamento térmico após tratamento ácido}

Analisando o difratograma na Figura 2 dos tratamentos térmicos para as amostras, foram identificados picos característicos do $\alpha$-quartzo (SiO2). Isso foi confirmado pelas fichas cristalográficas presentes no banco de dados Power Diffraction Files, esses dados corroboram com LEE (1999), que aponta que em temperaturas próximas de 500 ㄷ C há uma transição entre as fases cristalinas $\alpha$-quartzo e $\beta$-quartzo. Os picos observados apresentam maior cristalinidade do que os sem tratamento térmico (CORDEIRO, 2006). Além disso não foi observado nenhum sinal de estrutura amorfa.

De modo geral observou-se que as amostras sem tratamento térmico apresentaram halos característicos de materiais amorfos, em contrapartida as amostras com tratamento térmico não apresentaram essa característica, isso se deve as diferentes formas polimórficas da sílica que se rearranjam quando expostas a altas temperaturas, formando uma sílica mais cristalina que pode ser observada na Figura 2 (PUKASIEWICZ, 2001).

Para comprovação das fases observadas utilizou-se o programa Search Match e o banco de dados PDF (Power Diffraction Files), disponível no próprio programa, obtendo as fichas cristalográficas descriminadas na Tabela 1. 
Tabela 1. Identificação de picos em amostras de cinza do bagaço da cana através de Difração de raio $x$ e relação de fichas cristalográficas comparadas.

\begin{tabular}{l|c|c}
\hline AMOSTRA & FASE IDENTIFICADA & JCPDS \\
\hline Amostra 1 & QUARTZO & $2-471$ \\
Amostra 2 & QUARTZO & $2-458$ \\
Amostra 3 & QUARTZO & $2-458$ \\
$\begin{array}{l}\text { Amostra 2 } \\
\text { (Calcinada) }\end{array}$ & $\alpha$-QUARTZO & $3-427$ \\
$\begin{array}{l}\text { Amostra 3 } \\
\text { (Calcinada) }\end{array}$ & $\alpha$-QUARTZO & $5-490$ \\
\hline
\end{tabular}

Fonte: Próprio autor.

\section{CONSIDERAÇÕES FINAIS}

O processo de obtenção da cinza a partir de tratamentos ácidos, proporcionou as amostras uma calcinação mais rápida e direta, além de produzir um material com reduzido teor de estruturas amorfas.

As análises dos difratogramas de raio $x$ mostraram que houve mudança na cristalinidade do material após o emprego de tratamentos ácidos, porém o resultado foi melhor obtido depois que as amostras foram submetidas a calcinação.

Ambos tratamentos ácidos demonstraram eficiência na redução do halo amorfo, porém o tratamento com ácido nítrico e peróxido de hidrogênio apresentou maior eficiência. Nota-se ainda, que esses tratamentos possibilitaram maior correspondência entre os picos característicos do $\alpha$-quartzo.

A estrutura obtida pelos tratamentos empregados nas amostras ( $\alpha$-quartzo) é um material importantíssimo para aplicações industriais. Os tratamentos possibilitaram alterações nas propriedades físicas do material gerando cristais com alto grau de cristalinidade. Produzindo um material com potencialidade de utilização na produção de tintas, esmaltes, porcelanas, louças sanitárias, vidros convencionais, produção de dispositivos piezelétricos para medidas de grandezas físicas, entre outras áreas que não envolvam a agricultura.

\section{REFERÊNCIAS}

CORDEIRO, G. C. Utilização de cinzas ultrafinas do bagaço de cana-de-açúcar e da casca de arroz como aditivos minerais em concreto. Tese (Doutorado) - Universidade Federal do Rio de Janeiro, Rio de Janeiro, 2006.

GUZZO, P. L. Quartzo. In: LUZ, A.B.; LINS, F.A.F. (Eds.) Rochas e minerais industriais: usos e especificações. 2. ed. Rio de Janeiro: CETEM, 2008. p. 681-693.

LEE, J. D. Química inorgânica não tão concisa. 5. ed. São Paulo : Edgar Blücher, 1999.

OLIVEIRA, J. F. Obtenção de sílicas mesoporosas altamente ordenadas a partir da cinza da casca de arroz e do bagaço da cana de açúcar. Universidade de São Paulo, São Paulo, 2014. https://doi.org/10.11606/D.46.2014.tde-

25032015-094541

PAIVA, O.A. Durabilidade de concretos contendo cinza do bagaço da cana de açúcar. Tese (Doutorado) - Universidade Estadual do Rio de Janeiro, Rio de Janeiro, 2016.

PRADO, A. G. S.; FARIA, E. A.; PADILHA, P. M. Aplicação e modificação química da sílica gel obtida de areia. Quím. Nova, São Paulo, v. 28, n. 3, p.544-547, jun 2005.

PUKASIEWICZ, A. G. M. Tecnologia dos processos de fabricação IV. Ponta Grossa: Centro Federal de Educação Tecnológica do Paraná, 2001.

TERRA FILHO, M.; SANTOS, U. P. Silicose. J. Bras. Pneumol., São Paulo, v. 32, supl. 2, p. S41-S47, maio 2006. 